\title{
O CORPO IDEAL: REPRESENTAÇÃO DE CORPO NA SUBJETIVIDADE E CONTEMPORANEIDADE
}

\author{
EL CUERPO IDEAL: REPRESENTACIÓN DEL CUERPO EN LA SUBJETIVIDADY \\ CONTEMPORANEIDAD
}

\section{THE IDEAL BODY: BODY REPRESENTATION IN SUBJECTIVITY AND CONTEMPORANEITY}

RESUMO: O presente artigo, por meio de uma revisão bibliográfica, aborda a relação entre o sujeito e a imagem que ele tem do seu corpo, abarcando a influência recebida pelos meios de comunicação - mídia impressa, televisão e apelos publicitários, os quais contribuem para a massificação dos conceitos e valores sobre o corpo, que é visto como algo que pode ser manipulado ou modificado, tornando-se polo de profundos desejos e grande objeto de investimento. $\mathrm{O}$ culto ao corpo se mostra como característica desta época e encontra-se assentado na busca diária pela perfeição física, sendo capaz de superar qualquer problema e corresponder qualquer expectativa. Aborda-se, ainda, a subjetividade frente às constatações fenomenológicas e psicanalíticas, bem como a sua fragmentação como resultado do sujeito dividido na contemporaneidade. Quanto ao enfrentamento da questão, no que se refere ao padrão de corpo ideal, são aqui elencados possíveis malefícios e consequências psicológicas de uma busca desmedida.

PALAVRAS-CHAVE: Corpo. Subjetividade. Imagem. Contemporaneidade.

RESUMEN: A través de una revisión bibliográfica este artículo analiza la relación entre el sujeto y la imagen que tiene de su cuerpo, abarcando la influencia recibida por los medios de comunicación - medios impresos, televisión y atractivos publicitarios, que contribuyen a la masificación de conceptos y valores sobre el cuerpo, que se ve como algo que se puede manipular o modificar, convirtiéndose en un centro de profundos deseos y gran objeto de inversión. La adoración al cuerpo se muestra como una característica de este tiempo y se basa en la búsqueda de la perfección física a diario, pudiendo superar cualquier problema y corresponder a cualquier expectativa. También se aborda la subjetividad frente a los hallazgos fenomenológicos y psicoanalíticos, así como su fragmentación como resultado del sujeto dividido en la contemporaneidad. En cuanto a hacer frente a la pregunta, con respecto al estándar del corporal ideal, los posibles daños y consecuencias psicológicas de una búsqueda sin medida se enumeran aquí.

\section{PALABRAS CLAVE: Cuerpo. Subjetividad. Imagen. Contemporaneidad.}

\footnotetext{
${ }^{1}$ Faculdade Anhanguera, Pindamonhangaba - SP - Brasil. Docente no curso de Psicologia - UBM. Doutorado em Ciências da Saúde (FURG). ORCID: https://orcid.org/0000-0002-5537-4072. Email:marceladuponts@hotmail.com

${ }^{2}$ Centro Universitário de Barra Mansa (UBM), Barra Mansa - RJ - Brasil. Graduada no curso de Psicologia. ORCID: https://orcid.org/0000-0001-6260-8271.E-mail: josefa_kairos@hotmail.com
} 
ABSTRACT: This paper, through a bibliographical review, approaches the connection between the subject and the image it has of its body, covering the influence received by the media - print media, television and advertising appeals, which contribute to the massification of concepts and values about the body, which is seen as something that can be manipulated or modified, becoming a pole of deep desires and a great object of investment. The cult of the body shows itself as a characteristic of this time and is based on the daily search for physical perfection, being able to overcome any problem and meet any expectation. It also deals with subjectivity in the face of phenomenological and psychoanalytical findings, as well as its fragmentation as a result of the subject divided in contemporaneity. As to the confrontation of the issue, in what refers to the ideal body pattern, possible harm and psychological consequences of a disproportionate search are listed here.

KEYWORDS: Body. Subjectivity. Image. Contemporaneity.

\section{Introdução}

Ao avaliar os padrões sociais de beleza, cujos conceitos sofreram inúmeras influências, transformações e variações, no decorrer da historicidade do corpo, é possível identificar fatores psicológicos, sociais e culturais que se constituem como referências sobre o comportamento e a imagem subjetiva do ser humano. Isso porque os padrões de beleza são forças que, sobre a égide do capitalismo, fazem com que o corpo se torne um objeto de consumo, o que legitima as alterações por ele sofridas, em uma imposição cotidiana de padronização (FERRAZ; SERRALTA, 2007). Nesse sentido, o corpo é compreendido como uma construção mutável e/ou mutante, suscetível a intervenções concernentes ao desenvolvimento científico e à evolução tecnológica por meio da promoção cultural (GOELLNER, 2003, p. 28).

No universo psicológico do corpo ideal e da sua representação subjetiva e contemporânea, objeto de estudo deste trabalho, estão contidas discussões sobre a padronização do corpo no cotidiano, imposta pela sociedade. Tais discussões retratam o que os indivíduos sentem e desejam, como agem e criam, na visão capitalista, para que se tome uma forma de consumo que legitime as alterações corporais.

O sujeito moderno não demonstra, portanto, uma identidade naturalmente formada, mas sim construída frente às relações sociais. A busca pela imagem corporal estabelecida, um fenômeno impressionante na sociedade atual, acarreta custos elevados e riscos à saúde, gerando estresse, ansiedade e insatisfação com o próprio corpo (HALL, 2006, p. 75).

No caso do Brasil, a adequação a um padrão corporal socialmente imposto atingiu um limiar de fugacidade, o que traz a sensação de que tal estrutura "entra e sai de moda", em ritmo semelhante às tendências de determinada estação (GOLDENBERG, 2005, p. 70). 
Segundo dados do site G1, no ranking mundial, o país ocupa o segundo lugar em cirurgias plásticas ${ }^{2}$, perdendo apenas para os Estados Unidos.

Visto isso, este trabalho se justifica pela importância de compreender os fatores psicológicos, sociais e culturais que interferem diretamente nos parâmetros da imagem subjetiva das pessoas na busca pelo padrão ideal de corpo. Assim, tanto a sociedade quanto a propaganda midiática de massas impõem, como sinônimo de felicidade e de sucesso, um modelo corporal padronizado. Para melhor compreensão dos fatores acima elencados, fez-se necessário uma revisão bibliográfica acerca do tema, a qual constituiu o corpus deste trabalho.

No que concerne ao aspecto científico, é importante identificar as questões de baixo autoestima, inferioridade e distorção da imagem corporal, para que a pessoa possa se conscientizar dos riscos que tais procedimentos demasiados podem gerar na sua saúde mental e física (GANDRA; CÔRREA, 2018).

Tendo como objetivo principal compreender o fenômeno, frente a perspectivas fenomenológicas e psicanalíticas, este trabalho de pesquisa propõe uma reflexão sobre o corpo ideal e as suas consequências na atualidade. Especificamente, os objetivos que a pesquisa buscou alcançar foram: i) entender o modo como as mulheres enfrentam a imposição da beleza na atualidade; ii) descrever o processo de construção de corpo na contemporaneidade; iii) estabelecer as possíveis consequências da imposição social no referente ao padrão estético ideal; iv) constituir um apanhado dos fatores psicológicos resultantes da busca por uma imagem ideal, oposta à que realmente se apresenta.

\section{Desenvolvimento}

\section{Concepções corporais: a visão fenomenológica versus a psicanalítica}

Segundo a Fenomenologia, o corpo é o modo próprio de ser-no-mundo. O sujeito não tem apenas um corpo, o corpo não é apenas a sua morada, não é algo de que se pode despir, desvencilhar-se, mas é o próprio corpo, o seu corpo. Conforme Merleau-Ponty (2006, p. 203), citado por Gonçalves (2014, p. 18), é o corpo que realiza a abertura do eu ao mundo, colocando-o em situação: "O corpo é nosso meio geral de ter um mundo".

Ainda para Merleau-Ponty (2006, p. 278), como cita Gonçalves (2014), “o corpo é um eu natural, é o sujeito da percepção". Portanto, a percepção não é primariamente um ato de pensamento, mas um encontro entre o eu e o mundo, que se concretiza no corpo-vivido. 
Essa vivência do corpo, ao mesmo tempo que cede lugar a um saber sobre o objeto percebido, traz como correlato um saber sobre o próprio sujeito da percepção. Por isso Merleau-Ponty afirma que, no ato perceptivo, ao colocar o homem em contato com o mundo, o corpo conduz ao reencontro consigo mesmo e ao reconhecimento de que, afinal, "Eu sou o meu corpo". Estão imbricados aquele que percebe (o outro) e o percebido (o eu), opera uma forma de consciência habitando um corpo que é corpo: "A consciência do corpo invade o corpo, a alma se espalha em todas as suas partes" (MERLEAU-PONTY, 2006, p. 114).

Nesse sentido, o corpo também é um meio de comunicação latente de experiência horizontal, como um objeto no mundo. O corpo fundamenta-se em suas interações sociais, as quais mediadas pela consciência do mundo mediante a constituição física em questão (MERLEAU-PONTY, 2006, p. 122).

Na clínica psicanalítica, desde o início, mostra Freud, em suas teorizações, que o corpo sempre esteve em questão, conclusão que faz ao se deparar com a histeria na cena analítica à medida que as pacientes falavam sobre o que lhes causava sofrimento. Percebe-se que o corpo assume uma relevância clínica, sendo necessário considerá-lo, já que a fala possui o poder de "afetar o corpo e o pensamento" (BESSET et al., 2010, p. 01). A pulsão, conceito limítrofe, entre o orgânico e o psíquico, foi o termo utilizado por Freud (2007; 1915), como ressalta Fernandes (2014, p. 11), para explicar que o homem, afetado pela palavra, a qual repercute em representações psíquicas e deixa marcas que ficam registradas desde o seu nascimento, não é um ser meramente biológico.

Freud apresentou o corpo histérico como um corpo erótico, que não obedece às leis da anatomia, um corpo disputado pela satisfação pulsional. Freud $(1914 ; 1916)$, como ressaltou Besset (2008), instituiu um sujeito dividido pela linguagem. Habitado pelo inconsciente, ele não nasce com um corpo, sendo-lhe necessário construir um.

De veículo ou meio de satisfação pulsional, o corpo passa a ser também veículo ou meio de expressão da dor e do sofrimento. Um sofrimento que, às vezes, parece encontrar dificuldade para se manifestar em termos psíquicos. Desse modo, o corpo, como afirma Freud (2007;1930), é uma das fontes capazes de causar o mal-estar do homem. A Psicanálise, portanto, começa exatamente no ponto em que corpo e organismo se separam.

Sendo assim, dizer que Freud funda a distinção entre o corpo biológico e o corpo psicanalítico equivale a dizer, conforme salientado por Joel Birman (1991), que a psicanálise realiza uma passagem da lógica da anatomia para a lógica da representação. $O$ corpo da psicanálise é então um corpo atravessado pela linguagem: 
$\mathrm{Na}$ interpretação freudiana, os sintomas histéricos se articulam num sistema coerente, fundado na imagem do corpo, e não na estrutura do corpo, subordinada esta última às leis da distribuição anatômica dos órgãos e dos sistemas funcionais. $\mathrm{O}$ importante passa a ser como o histérico vivencia a sua corporalidade, ou seja, de que maneira investe as diferentes partes do seu corpo e as interpreta como superfícies dotadas de significação (BIRMAN, 1991, p. 141).

Freud, ressalta a importância de o analista estar atento a como o corpo se apresenta durante a sessão. Dessa forma, a psicanálise ouve o corpo para além de sua materialidade: o sintoma que o atravessa, a inibição que o paralisa, a angústia que o assola. No entendimento de Lacan (1985), "o gozo é propriedade do corpo vivo, que fala”. A princípio, ele situou o seu conceito na ordem imaginária, através do estádio do espelho. Momento favorecedor da constituição do EU, da imagem unificada do corpo.

Porém, antes desse período, há a experimentação de uma estrutura física despedaçada, com peças soltas que se confundem entre o que de fato é do sujeito e o que seria do outro. A partir do olhar de um terceiro, a criança estabelece o reconhecimento, no espelho, da unidade corporal, possibilitando divergir os limites entre o eu e o outro, ou seja, os limiares da própria estrutura física (FERNANDES, 2014).

O corpo, portanto, pode ser entendido como um conjunto de peças a partir das zonas erógenas, da fonte somática da pulsão e também dos próprios objetos pulsionais: seio, fezes, voz e olhar (LACAN, 1964; 2008). Além disso, a relação do sujeito com o corpo, destaca Lacan $(1964 ; 2008)$, está no cerne da experiência analítica. Faz-se ouvir e se dá a ver a partir de um encontro traumático do sujeito, uma perda sofrida, o seu encontro com o amor.

Segundo Lacan, explicam Coppus et al. (2014, p. 20), o corpo não é um só, ele é uma imagem na qual o eu se reconhece, é tecido de linguagem, marcado pelos significantes que trazemos do Outro. Ele é também real, possui furos, vazios que não se recobrem, conjunto de peças, com uma aparente unidade, que podem se soltar.

Isso torna compreensível a busca do homem e da ciência por um conhecimento e um controle sobre o corpo (COPPUS et al., 2014, p. 20), que pode ser atravessado pela linguagem e está condenado a um padecimento incurável, que repercute em um mal-estar na relação do indivíduo com o seu corpo (LACAN apud FERNANDES, 2014, p. 7).

\section{A subjetividade no processo de construção do corpo e da imagem: a luz da psicanálise e fenomenologia}


A psicanálise não fala de identidade nem de sua desconstrução, o que lhe interessa, e de que se tem ocupado, refere-se a uma outra dimensão do humano: a subjetivação (TATAGIBA, 2006, p. 24). Isto é, a constituição do sujeito como eu- corpo em constante movimento, impulsionado pelo desejo sempre inconsciente:

O conceito de inconsciente, por muito tempo, esteve batendo aos portões da psicologia, pedindo para entrar. A filosofia e a literatura quase sempre o manipularam distraidamente, mas a ciência não lhe pôde achar uso. A psicanálise apossou-se do conceito, levou-o a sério e forneceu-lhe um novo conteúdo (FREUD, 1940; 1938, p. 306 apud TATAGIBA, 2006, p. 24).

A subjetividade, em toda sua complexidade, é abrigada no corpo como lugar codificado. A condição de que o homem seja um corpo já contém mistérios suficientes, visto que o corpo é o sujeito, e não do sujeito, como já aludido. No entanto, Freud veio desmistificar o domínio absoluto sobre os pensamentos, as emoções e mesmo o corpo, ao trazer, no final do século XIX, para o centro das discussões, o conceito de inconsciente e uma nova compreensão para a sexualidade (TATAGIBA, 2006, p. 26).

Até Freud, o corpo era concebido como o lugar de representação do sujeito e sua expressão, o que supõe um eu e um corpo distintos. Depois de Freud, o corpo não é coisa nem obstáculo, mas parte integrante da totalidade do sujeito: "Meu corpo não é alguma coisa que eu tenho; eu sou meu corpo", confirma Birman, que ainda acrescenta:

A rigor, não existe o sujeito e seu corpo, numa dualidade e polaridade insuperáveis, mas sim um corpo-sujeito propriamente dito [...]. A separação entre corpo e psiquismo não é sustentável pela leitura freudiana da subjetividade (BIRMAN, 2003, p. 21).

Sigmund Freud, desde os seus textos teóricos iniciais, afirmava que um aparelho psíquico se constituiria somente na interação com um outro aparelho psíquico (FREUD, 1895). Estava aí enunciada, para a psicanálise, a importância e a ascendência de um outro humano no advento do sujeito e na concepção da subjetividade humana. Destaca-se a forma como o pai da psicanálise aponta que, no sujeito humano, existem um despreparo e um desamparo ante as ameaças do mundo externo. Isso confere ao sujeito uma total dependência dos cuidados de um outro ser humano. Surgimos e nos constituímos, portanto, no reflexo e na interação com esse outro.

Cabe ressaltar que o mito de Narciso, escolhido por Freud para ilustrar esse conceito fundamental da psicanálise, já aponta para o reflexo de um outro e do seu poder sobre a subjetividade de cada um de nós. Para abordar a dinâmica do narcisismo como constituição 
do eu pela imagem (no caso, a visual), Freud (1914) lança mão do mito, em referência à lenda grega de Narciso, que se apaixonou pelo seu próprio reflexo (FREUD, 1917, p. 148). É pela imagem unificadora e amada que o eu se constitui. Na dialética mítica e constitutiva do sujeito, a imagem visual é relevante. O corpo ganha visibilidade e, portanto, ganha forma.

Jacques Lacan concebe o "estádio do espelho" como um momento da evolução humana, no qual "a criança antecipa o domínio sobre sua unidade corporal através de uma identificação com a imagem do semelhante e da percepção de sua própria imagem no espelho" (ROUDINESCO; PLON, 1998, p. 194). Lacan, conforme Bandeira e Postigo (2015, p. 113), também utiliza o termo "outro ou Outro" como aquilo que vai designar uma alteridade especular, um outro imaginário, um lugar simbólico, a mãe, a cultura, enfim, um conceito que vai realizar o empoderamento do lugar da alteridade no advento e no funcionamento do psiquismo humano.

O ser humano, em sua concretude inicial, necessita unir-se ao outro como igual para então separar-se na diferenciação. Tais acontecimentos evidenciam-se na trajetória do ser indiferenciado e o ser da diferenciação, posto que, para a psicanálise, o sujeito não existe naturalmente desde o início, mas vai se constituindo. A relação dual, também dita complementar ou imaginária, inicia o processo de subjetivação (TATAGIBA, 2016, p. 37).

A relação de identificação é de fundamental importância para se entender, na Psicanálise, a constituição do eu-corpo e a dinâmica na distribuição de energia nos investimentos, tanto no primeiro eu-corpo (eu-de-todo-prazer) quanto no não-eu ou nos objetos externos (TATAGIBA, 2016, p. 38).

O eu-corpo começa a formular-se sob o domínio do princípio do prazer, característico do narcisismo primário. O eu-de-todo-prazer refere-se ao momento em que a criança se formula, de modo que todo o bom e prazeroso é ela, e o não bom/não-eu projeta a criança para fora de si e a constitui como mundo (TATAGIBA, 2016, p. 38). Enquanto o bom é introjetado, o desprazer é projetado para fora, confirmando assim a dinâmica inicial da diferenciação eu e mundo.

Em Fenomenologia, o conceito Merleau-Pontyano de corpo permite-nos pensar a constituição da subjetividade como um processo que se concretiza no corpo, a partir das suas vivências, dos seus movimentos, das suas percepções, das suas expressões e das suas criações.

Em suma, a subjetividade é o que caracteriza cada um, não no sentido de algo que nos define de modo acabado, imutável ou atemporal, pois ela é histórica e socialmente construída. A subjetividade se (re) faz na existência, conforme o sujeito apreende em seu contato com o mundo, com a alteridade (REIS, 2011, p. 47). 
Em âmbito geral, para GONÇALVES (2014, p. 21), a alteridade, do latim alteritas, que significa "ser o outro", tem a representação de se colocar ou se constituir no lugar do outro, e o outro no seu lugar, ou seja, apreender o outro na plenitude e, sobretudo, na sua diferença. Assim, na Fenomenologia, o eu se constitui na relação com o outro (GONÇALVES, 2014, p. 20).

Com esse ponto de vista, é possível afirmar que a subjetividade não é uma interioridade que se opõe à exterioridade, mas é a corporeidade, constituindo-se na dinâmica das relações corporalmente mediadas que o eu estabelece com o outro e com a sociedade. É da intersecção do próprio corpo com o mundo, da tensão dialética entre o eu e o outro, que emergem os sentidos em sínteses abertas, que constituem a subjetividade.

\section{Subjetividade líquida, fluida e fragmentada}

De acordo com Bauman (2001), conforme citado por Moreira e Jesus (2010, p. 326), a subjetividade contemporânea, postulada em um estado de fluidez, é algo que vem depois, é uma quebra, um deslocamento, baseado em um devir, um sujeito inacabado, líquido e plástico. Ainda segundo Moreira e Jesus (2010, p.327), Hall (2005) a considera como uma subjetividade fragmentária, incompleta, de identidades móveis, multimoduladas, híbridas e em permanente desconstrução e transformação. Além disso, Moreira e Jesus (2010, p. 328) ressaltam que, para Tavares (2004), a subjetividade contemporânea apresenta-se sob uma perspectiva coletiva e individual, conforme afirma Tavares:

O mundo pós-moderno pode ser considerado um pano de fundo, que promove os vetores psicossociais. A subjetividade, sob esse prisma, é regulada tanto pelo sistema simbólico social, que é da ordem do coletivo, quanto pelos aspectos pulsionais individuais, ambos em estado líquido.

Discursos que normatizam o corpo, sejam científicos, tecnológicos, publicitários, médicos e/ou estéticos, invadem a parte da vida simbólico-subjetiva do sujeito. Segundo Portela (2008), como destacam Moreira e Jesus (2010, p. 322): “O mundo contemporâneo determina novas formas de relação, afetando a constituição da subjetividade e, consequentemente, levando ao advento de um novo sujeito". O mundo, portanto, encontra-se diante de um sujeito em conflito e dividido, que escapa a qualquer tentativa de apreensão, pois está em transformação, em metamorfose, e em constituição (PORTELA, 2008 apud MOREIRA; JESUS, 2010, p. 324). 
A Modernidade e sua subjetividade líquida "diluíram" tudo aquilo que era - ou parecia ser - sólido, não colocando coisa alguma no lugar. Assumiu-se, portanto, uma impermanência, isto é, uma constante mudança de formas, em um processo que parece não ter previsão de término (SARAIVA; NETO, 2009). Aspectos que, segundo Lachi e Navarro (2012, p. 35), levam a compreender que o corpo se constitui não só como lugar de conflito e disputas dos saberes e discursos, mas também como um conflito do sujeito com o próprio corpo: ora ele o cultua; ora o nega e segrega; ora se apropria do outro; ora é apropriado por esse outro. É nesse jogo que se dá o processo de subjetivação do sujeito, que é chamado a assumir uma posição.

\section{Construção de identidades corporais}

Frente às mudanças tecnológicas, sociais e culturais dos tempos pós-modernos, a corporeidade passa a ser vista como parte integrante e inseparável de práticas discursivas, tendo o seu sentido de identidade individual, antes unificado e estável, agora fragmentado, composto não de uma única, mas de várias identidades (LACCHI; NAVARRO, 2012). Desse modo, a dificuldade já não é descobrir, inventar ou construir uma identidade, mas como impedi-la de ser demasiadamente firme e aderir depressa demais ao corpo (BAUMAN, 1998, p. 114).

Para Kristeva (1993), como observaram Vilhena; Novaes; Rosa (2014, p.259), os sujeitos contemporâneos se constituem num universo caracterizado pela aceleração de mudanças, que não mais asseguram a estabilidade identitária.

O espaço para a inscrição do pertencimento é o lugar em que ocorre a batalha dos processos de identificação e, junto à identidade e à cultura, liga-se e apoia-se, assim se estendendo à reflexividade da identidade do sujeito (GIDDENS, 2002). Desse espaço, fazem parte os discursos produzidos pela cultura, pela sociedade, pelas mudanças tecnológicas dos tempos pós-modernos, que se tornam "espaços" para a inscrição do pertencimento, ou seja, o lugar onde: i) ocorre a batalha dos processos de identificação e ii) os sujeitos se identificam, não ficando à parte do sistema. Isso configura um espaço simbólico na formação de identidades, de um eu "encarnado".

A modificação corporal é, portanto, um projeto não apenas de ordem física, mas de ordem identitária, à medida que está proporciona uma fórmula de fazer emergir outra versão de si mesmo. 
$\mathrm{O}$ ato de modificar recorrentemente o corpo implica uma espécie de ensaio identitário constante, enquanto expressão da (re) construção de uma subjetividade que já não se reconhece no corpo que a anuncia, ensaio esse tentado no acolhimento voluntário, e mais ou menos consciente, das propriedades simbólicas dos objetos que encarna e que tem significado para a pessoa que se modifica (FERREIRA, 2008, p. 62).

O sujeito se destaca por não possuir identidade fixa, essencial ou permanente; não se prendendo, portanto, a um único formato ou configuração. Ele "assume identidades diferentes em diferentes momentos; identidades que não são unificadas ao redor de um 'eu' coerente" (HALL, 2006, p. 13).

A relação mediada entre a identidade própria e aquela imposta pela sociedade de consumo torna-se então um grande valor.

\section{Enfrentamento: o sujeito e sua autoestima}

Ao longo do desenvolvimento humano, o corpo continua tendo forte relação com o psiquismo. A pressão e externados padrões de beleza acabam mobilizando o sujeito em sua percepção de si e, concomitantemente, na sua autoestima, uma vez que o conceito de belo está muito relacionado ao sentimento de aceitação (FERRAZ; SERRALTA, 2007). Ele é um comunicador de nossas emoções e um tradutor de nossos pensamentos e vontades. $\mathrm{O}$ movimento corporal fala, expressa e revela os mais íntimos desejos. Por meio dele - e com ele - descobre-se o mundo e as sensações. Contudo, muitas vezes, ele revela algo que não se quer mostrar, ou ainda é diferente, não correspondendo às expectativas (MELLO FILHO, 1992, p. 471).

Conforme GOUVEIA et al. (2005), Markus e Kitayama (1991) destacam que a forma de se olhar no espelho e se autoconceituar pode estar intimamente ligada a exigências de uma normativa sociológica de forma e aparência, as quais se aprendem na sociedade e na cultura. A autoestima, seja qual for o nível, é uma experiência íntima, estado da pessoa que não está em guerra consigo mesma ou com os outros. A falta de consciência de seu verdadeiro potencial pode levar a um desequilíbrio entre o que eu sou e o que eu gostaria de ser (FLORIANI et al., 2010, p. 4). De acordo com Markus e Kitayama (1991), como ressaltam GOUVEIA et al. (2005), caso essa experiência íntima não atinja um equilíbrio, o indivíduo passará a viver em contradição, fingindo ser o que ele gostaria, sem assumir a sua verdadeira identidade,

Autoestima, portanto, equivale ao querer bem a si mesmo. Quando diminuída, ela pode se refletir como complexo de inferioridade, sentimento de incapacidade, apatia, 
desânimo e outros sintomas que refletem indiferenças para com os próprios valores e a aparência, tanto física quanto mental. Para Egito (2010), como citado por Floriani et al. (2010, p.4). Geralmente, a baixa autoestima se apresenta como um estado de tristeza. Constrói-se e destrói-se a imagem corporal. Uma vez que ela não é fixa, ela então é definida a partir das interferências sociais que sofremos e dos hábitos que criamos, moldando o nosso aspecto de existir como seres corporais.

Para Portinari (2000), por meio do encaixe social, o indivíduo vai modificando o comportamento e valorizando aspectos do seu corpo, muitas vezes, antes impensados. A organização da imagem corporal, portanto, não é puramente neurológica nem mental. Acredita-se também que as emoções tenham um papel importante no desenvolvimento da imagem corporal (SHONTZ, 1990).

Há uma interação entre os lados fisiológico, neural e emocional, além do fator social. Um desses processos analisados separadamente tornaria a análise falha e incompleta. Mudanças em um deles podem ocasionar consequências na experiência do corpo (BARROS, 2005). Entretanto, a possibilidade concreta de aproximar o desejo da realidade é um dos aspectos que impulsionam e movimentam os sujeitos, uma maneira de sanar o sentimento de insatisfação consigo mesmo.

Na busca pela boa forma, diferentemente do que ocorre com a saúde, não há um ponto em que se possa dizer: "Agora que alcancei, posso parar e manter o que conquistei". A luta pela boa forma é uma compulsão que logo se transforma em vício. Cada dose precisa ser seguida de outra maior (BAUMAN, 2007, p. 123).

Quanto mais a pessoa for dominada e presa à autoimagem, ao ponto de ser dependente da própria aparência, mais distante ela estará de ser livre para o convívio feliz no mundo das diversidades (TOMMASO, 2010 apud FLORIANI et al., 2010, p. 6). O "estar bem consigo mesmo" necessita ser avaliado e alimentado diariamente, uma vez que a flutuação no humor, os acontecimentos cotidianos e as transformações ditadas pelo tempo são responsáveis pelo seu desequilíbrio. O ser humano lança mão de estratégias para reorganizar o self e reencontrar a homeostase.

Assim, o equilíbrio da experiência íntima produz um resultado positivo, gerando o equilíbrio do eu interior com o mundo, pois a boa autoestima exige que o eu interior esteja de acordo com o que eu manifesto no mundo (SILVA; SILVA, 2004). Atualmente, o corpo ideal tem escravizado o ser humano a uma busca incessante e desgastante. É possível encontrar 
condutas destrutivas como a anorexia, por exemplo, como alternativa de alcançá-lo (PORTINARI, 2000).

$\mathrm{O}$ ideal e o real acabam sendo distanciados. O indivíduo se perde frente à própria imagem, acarretando prejuízos emocionais, comportamentais, cognitivos e produtivos, que fazem com que ele desvalorize os aspectos positivos que possui (FERRAZ; SERRALTA, 2007).

Quando a fonte de mal-estar é o corpo, podemos percebê-lo como defeituoso, indesejado. Contudo, sendo esse aspecto o causador de grande sofrimento e da não aceitação de si mesmo, torna-se necessária a intervenção psicológica para alívio do sofrimento. Tal intervenção ainda proporciona satisfação interna, qualifica a relação consigo mesmo, eleva a autoestima, melhora tanto a imagem social quanto o desequilíbrio da conexão corpo e mente. Porém, instrumentalizar o sujeito a viver de maneira mais saudável e equilibrada é uma ação mais demorada, exigindo motivação e comprometimento pessoal em seu processo. A análise do mundo interno abre possibilidades de reflexão, de autoconhecimento e de julgamento crítico para questionar a maneira como o corpo vem sendo construído e de percepção de corpo, não só em sua estrutura, mas na maneira como ele é percebido e interpretado.

Assim, nota-se que, de fato, as pessoas se deixam seduzir por padrões de um corpo idealizado, produzidos por uma sociedade de lógica mercadológica, negando- se a buscar a reapropriação dos sentimentos e dos desejos há muito sufocados com a cumplicidade do mesmo (RODRIGUES; CANIATO, 2009, p. 682).

\section{Considerações finais}

Ao longo do tempo, os padrões de beleza foram influenciados por imposições psicológicas, sociais e culturais. Com isso, o processo de construção do corpo ideal tem sido, cada vez mais, estimulado por comportamentos e imagens subjetivas do indivíduo, produzindo um modelo de corpo idealizado, que foge ao real atingível, alvo de grande reforço midiático. Em relação à indústria corporal e à sugestionabilidade, observou-se que os indivíduos são expostos a diversas influências e ao bombardeio de informações. Isso reforça as imagens, invadindo e modificando a maneira de compreender e sentir as escolhas pessoais.

Na busca pelo corpo ideal, ditado pelo outro, a comunicação midiática, como reflexo do sentimento em relação a si mesmo, tem trazido consequências emocionais que podem levar a uma compulsão por procedimentos estéticos. Estes, por sua vez, determinam, subjetivamente, as atuais transformações na busca pela melhor aparência física que o corpo vem sofrendo. Assim sendo, fica clara a interferência da mídia na cultura de consumo de tudo 
o que se refere à perfeição da imagem corporal estabelecida pelo sistema capitalista. É inegável que a publicidade veiculada nos meios de comunicação de massa associa felicidade e sucesso a um modelo corporal padronizado, no qual a maioria das pessoas não se reconhece, ou seja, sobrepondo o ideal ao real. O corpo, portanto, deixa de pertencer ao sujeito corpóreo e se torna espelho de um modelo midiático idealizado, o que o leva a ser submetido a constantes práticas transformadoras da aparência.

Disso, decorre um sentimento de pertencimento e identidade a um grupamento social de referência, ou seja, composto por pessoas que detêm, ou se esforçam, para manter o corpo em consonância com os padrões ideais da beleza contemporânea.

A sua relevância encontra-se na urgência da conscientização acerca dos riscos de procedimentos estéticos invasivos aos quais o sujeito se submete em busca de um padrão irreal e efêmero de beleza. Além disso, a saúde mental é atacada por sentimento de culpa, angústia, frustração, o que leva à depressão e a inúmeros outros transtornos.

O objetivo central, frente a perspectivas fenomenológicas e psicanalíticas, foi compreendido e analisado por meio da reflexão sobre o mito do corpo ideal, tendo sido enumerado o processo de construção de corpo e imagem na contemporaneidade, estabelecendo-se as consequências da imposição social no referente ao padrão estético ideal. Isso sem descartar a análise dos fatores psicológicos associados à busca por uma imagem ideal frente ao real.

Podemos nos interrogar que lugar é este onde se situa o corpo na contemporaneidade, bem como sobre os saberes que atravessam o sujeito no social, uma vez que a corporeidade passa a ser vista como parte integrante e inseparável de práticas discursivas, se constituindo num lugar de conflito e disputas dos saberes, no qual o sujeito entra em crise com o próprio corpo, ora o cultuando, ora o negando, ora se apropriando do outro, ora sendo apropriado por esse outro.

A identidade individual, antes unificada e estável, tornou-se fragmentada, composta não de uma única, mas de várias identidades, os sujeitos contemporâneos se constituem num universo caracterizado pela aceleração de mudanças, que não mais asseguram a estabilidade identitária. Sendo assim, o que restou ao sujeito foi portar uma identidade passageira, líquida, inválida e coletiva, na busca frenética pelo consumo, na sua mente, ficou gravada a ideia de que para ser é preciso ter, o que caracteriza a servidão voluntária consumista atual.

A estrutura mental tornou-se um objeto de tal resplandecência que não ficou à parte do sistema. As imagens-normas acabam por destinar-se a todos aqueles que as veem, tratando-se de imagens corpóreas esplendorosas, cuidadosamente recriadas e moldadas, mas sem recheio, 
com uma escassez importante de valores e de vida interna. Invadindo a parte da vida simbólico-subjetiva, afetando a constituição da subjetividade e, consequentemente, levando ao advento de um novo sujeito, que em conflito e dividido, escapa a qualquer tentativa de apreensão, pois está em transformação, em metamorfose, e em constituição. Isso possibilita a inibição na vida psíquica, que, quando associada a uma deficiência, simboliza experiências significativas, tendo, por tanto, uma consistência frágil, em virtude de ter que estar sempre reconfigurada, falhando na atuação de ancoragem psíquica.

A Modernidade e sua subjetividade líquida "diluíram” tudo aquilo que era - ou parecia ser - sólido, não colocando coisa alguma no lugar. Assumiu-se, portanto, uma impermanência, isto é, uma constante mudança de formas, em um processo que parece não ter previsão de término. E, por meio de um diálogo incessante entre o que se vê e o que se é, pode produzir indivíduos insatisfeitos com a própria aparência. Um sujeito que se perde frente à própria imagem, acarretando prejuízos emocionais, comportamentais, cognitivos e produtivos, fazendo com que ele desvalorize os aspectos positivos que possui, atingindo o psiquismo e acarretando consequências danosas a sua autoestima, que, quando diminuída, pode se refletir como complexo de inferioridade, sentimento de incapacidade, apatia, desânimo e outros sintomas que refletem indiferenças para com os próprios valores e a aparência, tanto física quanto mental.

Geralmente, a baixa autoestima se apresenta como um estado de tristeza, sendo possível produzir o corpo como fonte de mal- estar e percebê-lo como defeituoso, indesejado. A falta de consciência de seu verdadeiro potencial pode levar a um desequilíbrio entre o que eu sou e o que eu gostaria de ser. Contudo, sendo esse aspecto o causador de grande sofrimento e da não aceitação de si mesmo, tornando-se necessária a intervenção psicológica para alívio do sofrimento, que isto possa acarretar.

O sujeito contemporâneo buscou um corpo imaterial, eterno, capaz de se movimentar por muitos espaços e ultrapassar todas as fronteiras do tempo, depois do direito ao rejuvenescimento, o direito à permanência. Nem que, para permanecer, seja preciso trocar de corpo. E não uma única vez, nem uma vez por todas. Trocar de corpo sem cessar. Talvez a forma mais arrogante de sobreviver seja a de querer permanecer eternamente. Ter total controle e manipulação do corpo é algo inviável, pois a natureza humana escapa, em termos, à domesticação: ele um dia vai envelhecer.

Sendo válido enfatizar a importância dos cuidados psicológicos, isso porque não se trata somente do corpo, mas também da mente, uma vez que os dois são intimamente ligados e dependentes. Assim, torna-se necessário instrumentalizar o sujeito a viver de maneira 
saudável e equilibrada, exigindo motivação e comprometimento pessoal em seu processo, abrindo espaço para uma reflexão interna de autoconhecimento, e também para o julgamento a cerca desta construção social desmedida da imagem corporal.

Visto isso, sem a pretensão de ter esgotado o tema proposto, este trabalho constitui-se em uma tentativa de avanço nos estudos acerca da percepção da imagem corporal, a qual é influenciada por diversos fatores socioculturais e envolvem um complexo emaranhado de questões psicológicas, sociais, culturais e biológicas, que determinam subjetivamente a busca pela melhor aparência física.

\section{REFERÊNCIAS}

BAUMAN, Z. O Mal-estar da Pós-Modernidade. 1. ed. Rio de janeiro: Jorge Zahar Ed. 1998.

BAUMAN, Z. Vida líquida. Rio de Janeiro: Jorge Zahar, 2007.

BESSET, V. L. E o corpo...fala? Disponível em:

fundamentalpsychopathology.org/8_cong_anais/MR_360v.pdf. Acesso em: 12 abr. 2019.

BIRMAN, J. Freud e a interpretação psicanalítica. Rio de Janeiro: Relume-Dumará, 1991.

BIRMAN, J. Mal-estar na atualidade: a psicanálise e as novas formas de subjetivação. 3. ed. Rio de Janeiro: Civilização Brasileira, 2001. 304 p.

COPPUS, A. N. et al. O medo que temos do corpo: a psicopatologia na vida cotidiana. Analytica, São João Del Rei, v. 3, n. 5, 2014.

FERNANDES, C O. A psicanálise mais além do silêncio do fenômeno psicossomático.

2014. 118 f. Dissertação (Mestrado em Psicologia) - Universidade Federal do Rio de Janeiro, Rio de Janeiro, 2014.

FERRAZ, S. B.; SERRALTA, F. B. O impacto da cirurgia plástica na autoestima. Estud. pesqui. psicol., Rio de Janeiro, v. 7, n. 3, p. 197-209, 2007.

FERREIRA, V. S. Marcas que demarcam. Lisboa: Imprensa de Ciências Sociais, 2008.

FLORIANI, F. M. et al. Autoestima e autoimagem: a relação com a estética. 2010.

Disponível em:

http://siaibib01.univali.br/pdf/Flavia\%20Monique\%20Floriani,\%20M\%C3\%A1rgara\%20Day ana\%20da\%20Silva\%20Marcante.pdf. Acesso em: 15 set. 2019.

GANDRA, A.; CÔRREA, D. Cinco já foram indiciados por mortes em procedimentos estéticos no Rio. Agência Brasil, Rio de Janeiro, 2018. Disponível em: 
https://agenciabrasil.ebc.com.br/saude/noticia/2018-08/cinco-ja-foram-indiciados-por-mortesem-procedimentos-esteticos-no-rio. Acesso em 15 set. 2019.

GIDDENS, A. Modernidade e identidade. Rio de Janeiro: Zahar Editor. Trad. Plínio Dentzien. 2002

GOELLNER, S. V. A produção cultural do corpo. In: LOURO, G. L. et al., (Org). Corpo, gênero e sexualidade: um debate contemporâneo na educação. Petropólis: Vozes, 2003.

GOLDENBERG, M. Gênero e corpo na cultura brasileira. Psicologia Clínica, São Paulo, v. 17, n. 2, p. 65-80, 2005.

GONÇALVES, A. S.; TEIXEIRA, J G. L. C. Corpos modificados ao extremo: o eu, o outro e a sociedade. 2014. 201 f. Tese (Doutorado em Sociologia) - Universidade de Brasília, Brasília, 2014.

HALL, S. A identidade cultural na pós-modernidade. Rio de Janeiro: DP\&A, 2006.

LACHI, P.; NAVARRO, P. O corpo moldado: corporeidade mediada e subjetiva. In: TASSO, I.; NAVARRO, P. (Orgs.). Produção de identidades e processos de subjetivação em práticas discursivas. Maringá: Eduem, 2012

MELLO FILHO, J. de. Psicossomática hoje. Porto Alegre: Artes Médicas, 1992.

MERLEAU-PONTY, M. Parcours deux: 1951-1961. Lagrasse: Verdier, 2000.

MOREIRA, A. P. G. M.; JESUS, M. Â. das G. S. de. A subjetividade fragmentada. CES Revista, Juiz de Fora, v. 24, p. 321-334, 2010. Disponível em:

https://www.cesjf.br/revistas/cesrevista/edicoes/2010/21_PSICOLOGIA_asubjetividadefragm entada.pdf. Acesso em: 15 set. 2019.

PORTINARI, D. B. A invasão dos belos corpos: corpo, técnica e fantasia na cena contemporânea. Psicologia Clínica, Rio de Janeiro, v. 12, p. 125-138, 2000.

RODRIGUES, A. A.; Caniato, A. M. P. "Corpo-mercadoria", sob controle e punição: Prenúncios de uma subjetividade aniquilada? Revista Mal-estar e Subjetividade, Fortaleza, v. IX, n. 2, p. 647-687, jun. 2009. Disponível em:

file://C:/Users/ALEXAN 1/AppData/Local/Temp/1634-15025-1-PB.pdf. Acesso em: 19 set. 2019.

SARAIVA, K.; VEIGA-NETO, A. Modernidade líquida, capitalismo cognitivo e educação contemporânea. Educação \& Realidade, v. 34, n. 2, p. 187-201, maio/ago. 2009.

SHONTZ, F. C. Body image and physical disability. In: CASH, T. F.; PRUZINSKY, T. (Eds.) Body images: development, deviance and change. New York: The Guilford Press, 1990.

SILVA, M. F. da; SILVA, M. J. P. da. A autoestima e o não verbal dos pacientes com queimaduras. Rev. esc. enferm., São Paulo, v. 38, n. 2, 2004. 
SOUZA, A. F. C. O percurso dos sentidos sobre a beleza através dos séculos: uma análise discursiva. 2004. 221 f. Dissertação (Mestre em Lingüística) - Universidade Estadual de Campinas, 2004.

TATAGIBA. V. M. R. O. O Corpo em situação de crise: imagens da subjetividade. 2006. 143 f. Dissertação (Mestre em Cognição em Linguagem) - Universidade Estadual Norte Fluminense, Goytacazes, 2006

VILHENA, J. de; NOVAES, J. de V.; ROSA, C. M. A sombra de um corpo que se anuncia: corpo, imagem e envelhecimento. Rev. Latinoam. Psicopat. Fund., São Paulo, v. 17, n. 2, p. 251-264, jun. 2014. Disponível em: https://www.scielo.br/pdf/rlpf/v17n2/1415-4714-rlpf-1702-00251.pdf. Acesso em: 15 set. 2019.

\section{Como referenciar este artigo}

SOARES, M. D.; BARBOSA, J. F. O corpo ideal: representação de corpo na subjetividade e contemporaneidade. Doxa: Rev. Bras. Psico. e Educ., Araraquara, v. 22, n. esp. 1, p. 238254, out., 2020. e-ISSN: 2594-8385. DOI: https://doi.org/10.30715/doxa.v22iesp.1.14131

Submetido em: 20/04/2020

Revisões requeridas: $15 / 06 / 2020$

Aprovado em: 20/08/2020

Publicado em: 30/09/2020 